\title{
Recomendaciones. Concepto, naturaleza y atributos
}

Ysmael Francisco Núñez Sáenz*

http://dx.doi.org/10.21503/lex.v10i9.377

* Abogado por la Pontificia Universidad Católica del Perú, con estudios de postgrado en el Centro de Altos Estudios Nacionales (CAEN), la PUCP (Política Jurisdiccional), la Comunidad Andina de Naciones (Convenio Hipólito Unanue), The George Washington University (Gobernabilidad y Gerencia Política) y The National Democratic Institute (NDI) (Reforma Política y Salud). 



\section{RESUMEN}

El presente artículo constituye una contribución al desarrollo conceptual y normativo del Sistema Nacional de Control a partir del estudio de uno de los conceptos y herramientas más frecuentes dentro del mismo: las recomendaciones. En dicho contexto, y tras el análisis del marco normativo e histórico que sustenta esta atribución del sistema, se parte de la definición contenida en el numeral IV de la NAGU 4.40, para deducir -a través del método exegéticocada uno de sus atributos: causalidad, finalidad, razonabilidad, competencia, especificidad y oportunidad, los mismos que serán analizados en detalle, en busca de sus límites normativos y fácticos, concreción final de aquella garantía denominada debido proceso de control.

\section{MARCO NORMATIVO}

Para la Ley 27785 Ley Orgánica del Sistema Nacional de Control (LOSNC), la atribución de emitir recomendaciones encuentra sustento en sus artículos $2^{\circ}, 6^{\circ}, 10^{\circ}, 15^{\circ}$ inc. b) y e), $22^{\circ}$ inc. c), s) y x), y 420 inc. d), complementados por la Resolución 162-95-CG que aprobó las normas de auditoría gubernamental, la Resolución 279-2000-CG que aprobó la Directiva de verificación y seguimiento de implementación de recomendaciones y la Resolución 5632005-CG que aprobó los criterios de determinación de la situación de las recomendaciones. No obstante, y como dato histórico, debemos señalar que el Sistema Nacional de Control no siempre ostentó la facultad de "recomendar". Desde su creación como una repartición administrativa del Ministerio de Economía en 1930 (Ley 6784), pasaron más de cuarenta años para que la Contraloría General viese plasmada dicha posibilidad en el art. 12 inc. h) del Decreto Ley 19039, el mismo que ha sido consistente precedente del art. 16 inc. b) de la anterior ley del SNC, Dec. Ley 26162, y del actual art. 15 inc. b) de la LOSNC. En cualquier caso, estas normas revelan que con sus recomendaciones, el SNC y la CG han pretendido en esencia "mejorar la capacidad y eficiencia de las entidades en la toma de sus decisiones y en el manejo de sus recursos”. 


\section{CONCEPTO Y NATURALEZA}

En la LOSNC no se observa una definición explícita sobre este concepto; sin embargo, el numeral IV de la NAGU 4.40 señala que las recomendaciones “(...) constituyen las medidas sugeridas a la Administración de la entidad examinada, orientadas a promover la superación de las observaciones o hallazgos emergentes de la evaluación de la gestión. Serán dirigidas a los funcionarios públicos que tengan competencia para disponer su aplicación. El informe debe contener recomendaciones constructivas que, fundamentadas en los hallazgos y conclusiones correspondientes, propicien la adopción de correctivos que posibiliten mejorar significativamente la gestión y/o el desempeño de los funcionarios y servidores públicos, con énfasis en el logro de los objetivos, metas y programas de la entidad auditada dentro de parámetros de economía, eficiencia y eficacia. Las recomendaciones deben estar encaminadas a superar las causas de los problemas observados, se referirán a acciones específicas y estarán dirigidas a quienes corresponde emprender esas acciones. Además, es necesario que las medidas que se recomienden sean factibles de implantar y que su costo corresponda a los beneficios esperados. Las recomendaciones deberán contener la descripción de cursos de acción para optimizar el cumplimiento de metas y objetivos institucionales, sectoriales y nacionales. (...)”. ${ }^{1}$

\section{ATRIBUTOS}

De la precitada definición, podemos advertir que toda recomendación para ser exigible como tal debe reunir al menos seis atributos a saber: causalidad, finalidad, razonabilidad, competencia, especificidad y oportunidad.

En cuanto al atributo de causalidad, la NAGU 4.40 establece que toda recomendación debe estar “(...) fundamentada en los hallazgos y conclusiones (...) y en consecuencia (...) estar encaminada a superar las causas de los problemas observados (...).” De ello se desprende que la identificación de la causa de los problemas observados es vital para la elaboración de recomendaciones, y en ello hay que advertir que no se trata de superar cualquier tipo de causa (causa material, final, eficiente o -más recientemente- probable) sino aquella causa adecuada que generó el evento observable, tal cual lo establece la definición de relación causal prevista en la novena disposición final de la LOSNC.

Sobre la finalidad de toda recomendación, la precitada definición establece que aquella debe “(...) promover la superación de las observaciones o hallazgos (...), mejorar significativamente

1 Visto así, el tema pareciera que la naturaleza de una recomendación es sugerir y propiciar más que ordenar; sin embargo, más allá de su imprecisión semántica, lo que la LOSNC pretende es exactamente lo contrario, es decir, busca que sus recomendaciones posean carácter vinculante para los titulares de las entidades (o funcionarios responsables) encargados de su implementación, pues su incumplimiento acarrea responsabilidad. Ello nos deja como primera conclusión que el SNC llama recomendaciones a lo que en sí son verdaderos mandatos. 
la gestión y/o el desempeño de los funcionarios y servidores públicos (...) y (...) optimizar el cumplimiento de metas y objetivos institucionales, sectoriales y nacionales (...)". Como vemos, si bien una finalidad primera de toda recomendación es superar los problemas observados, su propósito último es buscar mejoras significativas y optimización de la gestión. Esta característica implica para el auditor una gran responsabilidad, pues si bien toda recomendación está llamada a influir en la gestión institucional, le está vedado direccionarla. En los hechos, el límite de esta atribución no es claro; no obstante, lo que sí es claro es que "(...) ninguna entidad o autoridad, funcionario o servidor público o terceros pueden oponerse, interferir o dificultar el ejercicio de sus funciones y atribuciones de control". ${ }^{2}$ En cualquier caso, se evidencia que toda recomendación debe tener vocación de infalibilidad, pues si yerra en su finalidad, lejos de corregir debilidades institucionales podría dar origen a otras y distorsionar así el propio control, que se vería en la necesidad de ser juez y parte de sus desaciertos, negando con ello uno de los principios básicos del sistema: el principio de objetividad. ${ }^{3}$

En tercer lugar, el atributo de razonabilidad encuentra sustento como tal cuando la NAGU 4.40 exige que las recomendaciones sean "(...) factibles de implantar y que su costo corresponda a los beneficios esperados (...)", respetando a su vez los “(...) parámetros de economía, eficiencia y eficacia (...)".

Ello, a la luz de lo dispuesto por el art. 9o de la LOSNC y por el art. IV del Título Preliminar (numeral 1.4) de la LPAG, implica que toda recomendación tiene por fuerza un impacto presupuestal.

Resulta evidente, por tanto, que toda recomendación debería resistir un análisis costobeneficio que valide su factibilidad, lo cual es concordante con el parámetro de economía, que la LOSNC define como la relación dada "(...) entre los términos y las condiciones bajo las cuales se adquieren los recursos, sean estos financieros, humanos, físicos o de sistemas computarizados, obteniendo la cantidad y el nivel apropiado de calidad al menor costo, en la oportunidad y en el lugar requerido". ${ }^{4}$ Por su parte, la aplicación del parámetro (principio) de eficiencia, recogido por la nueva Ley Orgánica del Poder Ejecutivo, ${ }^{5}$ impone que el mencionado análisis costo-beneficio no se realice solo en abstracto, es decir, en función de la propia recomendación, sino que debe ser realizado también en concreto, tomando para ello como referencia imprescindible el presupuesto institucional dedicado al rubro en donde aquellas tienen impacto. ${ }^{6}$

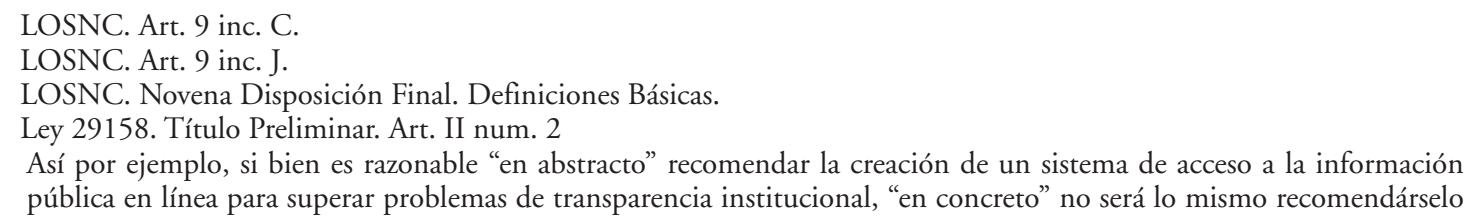


En cuarto lugar y en cuanto al atributo de competencia, la definición bajo análisis establece que las recomendaciones “(...) serán dirigidas a los funcionarios públicos que tengan competencia para disponer su aplicación (...) y que (...) estarán dirigidas a quienes corresponde emprender esas acciones(...)", lo que en los hechos implica que todo auditor deberá observar atentamente tanto el ROF como el MOF institucional cuando de imponer recomendaciones se trata, pues de no existir esta correspondencia entre el mandato impuesto y las atribuciones del funcionario obligado se atentaría contra el principio de legalidad.

En quinto lugar, debemos señalar que el atributo de especificidad, también se deriva de la definición bajo comentario cuando esta señala que toda recomendación "(...) se referirá a acciones específicas y (...) deberá contener la descripción de cursos de acción (...)”. No obstante, este atributo merece una precisión adicional, pues tiende a confundir el concepto de recomendación con el de medida correctiva, y con ello el momento de implementación de una recomendación. Así, podemos apreciar que las recomendaciones son el producto del ejercicio de una potestad por parte del auditor, en tanto que las medidas correctivas son la consecuencia del cumplimiento de un deber por parte del funcionario encargado de la implementación de las primeras. De estas diferencias colegimos que el atributo de especificidad no constituye una herramienta de gestión en manos del auditor, sino simplemente una exigencia de seriedad de la recomendación impuesta y/o un supuesto de colaboración en el diseño de uno entre varios posibles cursos de acción que el funcionario responsable elegirá, sobre la base de una mayor información disponible, atendiendo a principios complementarios tales como el de especialidad cuantitativa, transparencia o vigencia tecnológica, entre otros. Por ende, los auditores no deberían perseguir el escrupuloso cumplimiento de la acción específica recomendada para tenerla por implementada, sino que deberían atender a la superación de los problemas observados, aun cuando para alcanzar dicho fin el funcionario responsable hubiese variado (en ejercicio legítimo de sus facultades) el curso de acción propuesto por el auditor.

Finalmente, y con acertado criterio, la normatividad vigente exige que las recomendaciones cumplan con el atributo de oportunidad, pues de poco valdría que cumplan escrupulosamente con cada uno de los atributos analizados hasta aquí, si por razones temporales -como en el supuesto de deslinde de responsabilidades- no pudieran ejecutarse. Sin embargo, este atributo no se advierte de la NAGU 4.40 que hasta aquí nos ha servido de marco normativo, sino de lo dispuesto por el art. $15^{\circ}$ inc. b) de la LOSNC, cuando señala que es una atribución del sistema "formular oportunamente recomendaciones". El concepto de oportunidad, por su parte, está ligado íntimamente al de temporalidad, en función del cual toda recomendación deberá ser impuesta tomando en consideración el plazo que la norma le otorga al encargado

al titular de un pliego presupuestal que hacerlo a la máxima autoridad administrativa de una unidad ejecutora. 
de su implementación, y en dicho marco, deberán tomarse en cuenta tanto los plazos de prescripción de la acción administrativa, penal y/o civil como los plazos de ejecución presupuestal, de procesos de selección, de programación, etc., según el carácter de cada recomendación.

\section{CONTROL DE CALIDAD}

En primer lugar, debemos señalar que toda recomendación derivada de un informe de control comparte con este, la naturaleza de acto de administración interna, según lo establece el art. $24^{\circ}$ de la LOSNC, por lo cual, en principio, no son -a diferencia de los actos administrativos- objeto de impugnación. Por su parte, el art 9o inc. c) de la LOSNC establece que las recomendaciones no son objeto de cuestionamiento, con lo cual el círculo parece cerrarse a toda posibilidad de oposición por parte de los obligados a su cumplimiento. Sin embargo, las recomendaciones y los informes de los cuales son parte están sujetas al control de la CGR (LOSNC, art. 24\%), el cual si bien está diseñado para ser impulsado de oficio, puede ser requerido de parte en ejercicio del derecho de petición administrativa que consagra el art. $2^{\circ}$ inc. 20 de la Constitución Política así como los artículos $106^{\circ}$ y $107^{\circ}$ de la LPAG. No obstante, desde nuestro punto de vista, la Contraloría General debería establecer un mecanismo ad hoc de control de calidad de recomendaciones cuando el obligado argumente el incumplimiento de alguno de sus atributos y ello a su vez tenga un impacto directo en la viabilidad de su cumplimiento; de lo contrario, la realidad puede determinar el incremento del índice de incumplimiento de recomendaciones. 


\section{CONCLUSIONES}

1. El objetivo de toda recomendación es contribuir a la mejor gestión de las entidades sujetas al control gubernamental.

2. En cualquier caso, toda recomendación, para poder ser implementada, debería observar cinco atributos que su propia definición le impone: causalidad, finalidad, razonabilidad, competencia y especificidad.

3. El incumplimiento de los atributos de toda recomendación puede ser controlado, de oficio o a petición de parte, por la Contraloría General en el ejercicio de su potestad de control de calidad, prevista en el art. $24^{\circ}$ de la LOSNC.

4. La Contraloría General debería establecer un mecanismo ad hoc de control de calidad de recomendaciones cuando el obligado argumente el incumplimiento de alguno de sus atributos y ello a su vez tenga un impacto directo en la viabilidad de su cumplimiento.

5. La adecuada diferenciación de los conceptos complementarios de recomendación y medida correctiva permite advertir el momento exacto de su implementación. 